\title{
LOW LEVEL LASER THERAPY (LLLT) FOR CEREBRAL PALSY
}

\author{
${ }^{*}$ Kazuaki Tsuchiya M.D. ${ }^{2}$, Takashi Harada M.D. ${ }^{1}$, Nobuyuki Ushigome M.D. ${ }^{1}$, \\ Ikuko Ohkuni M.D. ${ }^{1}$, Toshio Ohshiro M.D., Ph.D. ${ }^{3}$, Yoshiro Musya M.D. ${ }^{4}$, \\ Kazuhiro Mizutani M.D. ${ }^{4}$, Yu Maruyama M.D. ${ }^{5}$ and Toru Suguro M.D. ${ }^{2}$ \\ 1: Rehabilitation Medicine and 2: Orthopaedic Surgery Toho University, Tokyo; 3: Japan \\ Medical Laser Laboratory, Shinanomachi, Tokyo; and Departments of 4: Orthopaedic Surgery, \\ Obhashi Hospital and 5: Plastic Surgery, Toho University, Tokyo, Japan
}

\begin{abstract}
Spasticity in cerebral palsy (CP) patients is a critical factor preventing voluntary movement, and can also be associated with involuntary clonus. Low reactive-level laser therapy (LLLT) has been reported as having good overall efficacy in $\mathrm{CP}$ patients and also in controlling clonus. The present study was designed to evaluate LLLT in the clinical setting to attenuate spasticity in severely handicapped CP patients. We treated $20 \mathrm{CP}$ patients with near infrared $(830 \mathrm{~nm})$ LLLT (16.2 $\mathrm{J} / \mathrm{cm} 2 /$ point, once/week over 10 weeks) as a clinical study at our university hospital and a hospital connected with our university. For spasticity of the hip adductor muscle, the obturator nerve was the target for LLLT, and the tibial nerve was irradiated in the case of triceps surae muscle spasticity. LLLT was indicated for the 10 sessions and the degree of attenuation of spasticity was assessed after the final session. Some degree of efficacy and treatment latency was seen in 14 (70\%) of the 20 patients, 5 evaluated as excellent, 6 as very good and 3 as fair. Little or no change was seen in the remaining 6 patients, and in no patient did the symptoms worsen. We concluded that LLLT was an efficacious treatment option in the conservative treatment of CP patients, that it was easilyapplied, non-invasive and pain-free, and that it did not have any adverse side effects.
\end{abstract}

Key Words: Low level laser therapy, cerebral palsy, spasticity, clonus

\section{Introduction}

There are several types of cerebral palsy (CP), such as the spastic type, athetotic type, mixed type, hypotonic type, ataxic type, and so on. The spastic type involves severe spasticity characterized by increased tonus in the affected muscles resulting in resistance to passive stretch, velocity-dependent and asymmetric about joints. Exaggerated deep tendon reflexes and clonus are additional manifestations. Severe spasticity is a critical preventative factor for facilitating voluntary movement conservative treatments have been indicated in the attenuation of patient spasticity, such as medication, therapeutic exercise, bracing, Botox muscular

\footnotetext{
Addressee for Correspondence:

Takashi Harada

Department of Rehabilitation Medicine Toho University

School of Medicine

Address: 6-11-1 Ohmorinishi Ohtaku Tokyo 143-8541

Japan

Tel: +81-3-3762-4151

Fax: +81-3-3768-6117

E-mail: haradata@med.toho-u.ac.jp
}

injection, phenol nerve block and so on.

In 1985, Walker reported that low level laser therapy (LLLT) attenuated the clonus element of spasticity. (1) Following this, our group reported that LLLT efficiently attenuated spasticity caused by pyramidal tract disorder of brain and spinal cord. ${ }^{(2)}$ The purpose of the present investigation was to evaluate LLLT effects in the treatment of $\mathrm{CP}$ patients in terms of spasticity attenuation.

\section{Subjects and Methods}

\section{Subjects}

Twenty patients with the spastic type of CP comprised the study subjects, who had been treated in our university hospital and a hospital connected with our university, from 2001 to 2006 (Table 1). All patients were severely physically handicapped, and had been issued

Manuscript received: January 2008

Accepted for publication: Feburary 2008 


\section{ORIGINAL ARTICLES}

Table 1: Case Outlines of Cerebral Palsy Patients

\begin{tabular}{|c|c|c|c|c|c|c|c|c|}
\hline \multirow{2}{*}{ case } & \multirow{2}{*}{ age } & \multirow{2}{*}{ sex } & \multirow{2}{*}{ Paretic type } & \multirow{2}{*}{ Irradiation part* } & \multirow{2}{*}{$\begin{array}{l}\text { Locomotive } \\
\text { Function }\end{array}$} & \multicolumn{2}{|c|}{$\begin{array}{l}\text { Frequency of Ankle } \\
\text { Clonus Indication }\end{array}$} & \multirow{2}{*}{ evaluation } \\
\hline & & & & & & $\begin{array}{l}\text { Before } \\
\text { irradiation }\end{array}$ & $\begin{array}{c}\text { After } \\
\text { irradiation }\end{array}$ & \\
\hline 1 & 6 & $\mathrm{M}$ & paraplegia & $\mathrm{T}$ & cane gait & 4 & 0 & excellent \\
\hline 2 & 4 & $\mathrm{~F}$ & tetraplegia & $\mathrm{T}, \mathrm{O}$ & bedridden & 6 & 2 & good \\
\hline 3 & 5 & M & hemiplegia & $\mathrm{T}$ & self gait & 5 & 1 & excellent \\
\hline 4 & 22 & $\mathrm{~F}$ & paraplegia & $\mathrm{T}$ & cane gait & 10 & 5 & good \\
\hline 5 & 8 & $\mathrm{~F}$ & paraplegia & $\mathrm{T}, \mathrm{O}$ & cane gait & successive & 5 & good \\
\hline 6 & 13 & M & paraplegia & $\mathrm{T}$ & wheelchair & 8 & 8 & no change \\
\hline 7 & 10 & M & tetraplegia & $\mathrm{T}, \mathrm{O}$ & wheelchair & 7 & 7 & no change \\
\hline 8 & 7 & $\mathrm{~F}$ & tetraplegia & $\mathrm{T}, \mathrm{O}$ & wheelchair & 5 & 5 & no change \\
\hline 9 & 17 & $\mathrm{~F}$ & tetraplegia & $\mathrm{T}, \mathrm{O}$ & wheelchair & 6 & 2 & fair \\
\hline 10 & 19 & M & tetraplegia & $\mathrm{T}, \mathrm{O}$ & wheelchair & 7 & 2 & fair \\
\hline 11 & 29 & M & tetraplegia & $\mathrm{T}, \mathrm{O}$ & bedridden & 7 & 6 & no change \\
\hline 12 & 15 & M & hemiplegia & $\mathrm{T}$ & self gait & 6 & 1 & excellent \\
\hline 13 & 14 & M & hemiplegia & $\mathrm{T}$ & self gait & 6 & 4 & fair \\
\hline 14 & 17 & $M$ & hemiplegia & $\mathrm{T}$ & self gait & 7 & 1 & excellent \\
\hline 15 & 23 & $\mathrm{~F}$ & paraplegia & $\mathrm{T}$ & cane gait & 5 & 5 & no change \\
\hline 16 & 24 & M & paraplegia & $\mathrm{T}$ & cane gait & 6 & 2 & excellent \\
\hline 17 & 4 & M & paraplegia & $\mathrm{T}$ & cane gait & 4 & 1 & good \\
\hline 18 & 8 & $\mathrm{M}$ & paraplegia & $\mathrm{T}$ & cane gait & 5 & 2 & good \\
\hline 19 & 14 & $\mathrm{~F}$ & paraplegia & $\mathrm{T}$ & cane gait & 6 & 2 & good \\
\hline 20 & 16 & $\mathrm{~F}$ & paraplegia & $\mathrm{T}$ & cane gait & 6 & 6 & no change \\
\hline
\end{tabular}

*(T : Tibial nerve, $\mathrm{O}:$ Obturator nerve $)$

with Physically Handicapped Person's Certificates from grades 3 to 1 . There were 12 male patients and 8 female patients. Ages ranged from 4 to 29 years old, with an average age of $13.8 \mathrm{yr}$.

The study was conducted under the principles of the Declaration of Helsinki (2004). After having had the study explained to them in full, all patients, or their families where appropriate, gave written informed consent to participate in the study.

\section{Methods}

The LLLT system used was a gallium aluminum arsenide (GaAlAs) diode laser (MDL-2001, Matsushita Electric Corporation, Tokyo, Japan), delivering $60 \mathrm{~mW}$ at $830 \mathrm{~nm}$ in continuous wave, with optional frequency modulation settings. CW was used in the present study. The spot size at tissue was $1.4 \mathrm{~mm}$ in diameter, and the incident power density or irradiance was 60
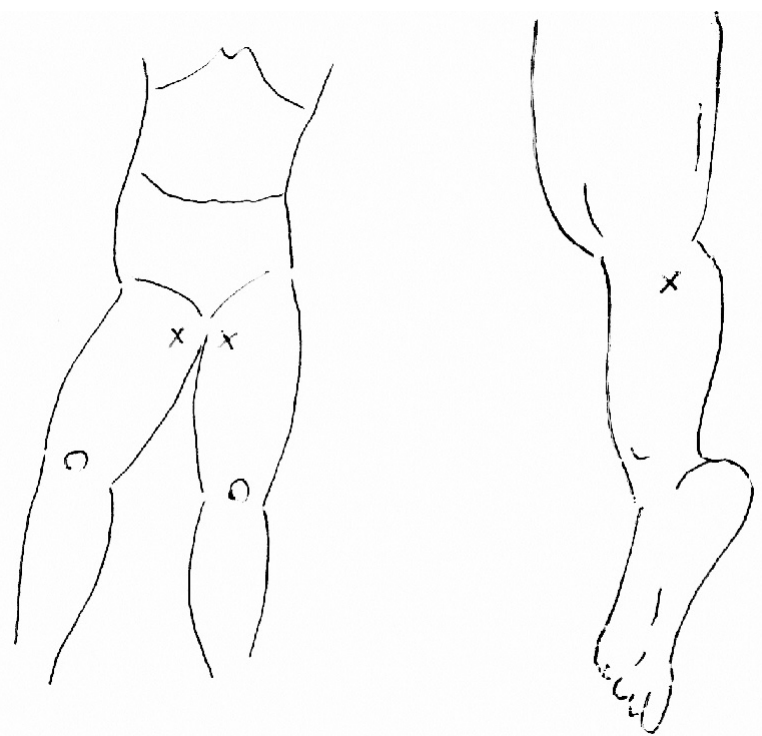

Fig. 1: LLLT irradiation targets Left side $\mathrm{x}$ mark: obturator nerve Right side $\mathrm{x}$ mark: tibial nerve 
Table 2: Low Level Laser Therapy device Specifications

\begin{tabular}{|c|c|}
\hline Laser Element & $\begin{array}{c}\text { Semiconductor Laser Diode } \\
\text { Ga-Al-As: Gallium - Aluminum - Arsenide }\end{array}$ \\
\hline $\begin{array}{c}\text { Model \& } \\
\text { Manufacturer }\end{array}$ & $\begin{array}{c}\text { MDL-2001 model } \\
\text { Matsushita Electric Corporation, Tokyo, Japan }\end{array}$ \\
\hline wavelength & $830 \mathrm{~nm} \pm 5 \mathrm{~nm}$ \\
\hline output & $60 \mathrm{mw} \pm 20 \%$ \\
\hline mode & continuous wave mode \\
\hline irradiation time & $30 \mathrm{sec}$. \\
\hline energy density & $16.2 \mathrm{~J} / \mathrm{cm}^{2}$ \\
\hline power supply & $100 \mathrm{VAC}, 50-60 \mathrm{~Hz}$ \\
\hline
\end{tabular}

$\mathrm{mW} / \mathrm{cm}^{2}$ (Table 2).

The target points for LLLT irradiation were the obturator nerve which innervates the hip adductor muscle, and near the tibial nerve which innervates the triceps surae muscle (Fig 1). The laser handpiece was applied with mild pressure to the skin over these targets. Each treatment session consisted of 3 irradiations over each target of $30 \mathrm{sec}$ each, delibvering an energy density or radiant fluence per point of $16.2 \mathrm{~J} / \mathrm{cm}^{2}$. We irradiate the same target points three times each. Treatment sessions were once per week for 10 weeks.

We evaluated the immediate effects after each session, and the and lasting effects after the final session. Table 3 shows the evaluation criteria. To evaluate the immediate effects, we checked changes in the frequency of ankle clonus indication before and after each irradiation, and the range of motion (ROM) of the hip joint and ankle joint.

To evaluate the latency of the effects after the $10^{\text {th }}$ irradiation, we continuously assessed changes in the patients' gait pattern, any reduction in the amount of family assistance required (dressing/undressing, support of sitting position), and how much the patients' families were satisfied with the treatments.

\section{Results}

Results were evaluated as excellent, good, fair, little or no change or worse, as shown in Table 3. Fourteen of the $20 \mathrm{CP}$ patients showed some degree of change, with 5 cases evaluated as excellent, 6 as good, and 3 as fair. In the 6 remaining patients, little or no change was seen but their conditions did not worsen, and there were not any side effects.

Cases with excellent effects had the following improve-
Table 3: Effect Evaluation Criteria

\begin{tabular}{|c|l|}
\hline excellent & $\begin{array}{l}\text { - the duration of the effect was more than } 1 \text { day } \\
\text { - significant reduction in the frequency of ankle } \\
\text { clonus indication }\end{array}$ \\
\hline good & $\begin{array}{l}\text { - the duration of the effect was } 1 \text { day or less } \\
\text { - some reduction in the frequency of ankle clonus } \\
\text { indication }\end{array}$ \\
\hline fair & - subjective improvement \\
\hline no change & $\begin{array}{l}\text { - pain } \\
\text { - sensory disturbance } \\
\text { - side effects, etc. }\end{array}$ \\
\hline
\end{tabular}

ments: disappearance of ankle clonus

- increased range of joint motion (ROM)

- effects lasting for more than 1 day

Cases with good effects had the following improvements:

- frequency of ankle clonus indications decreased.

- improved gait pattern

- effects lasting less than one day

Cases with fair effects had the following improvements:

- no change in the frequency of ankle clonus indications

- subjectively attenuated spasticity of legs

- putting on a brace more easily managed

In terms of duration:

- We were able to investigate to what degree treatment could lessen the frequency of ankle clonus indications as one of the immediate effects

- As for the lasting effects, we had 5 cases with excellent effects which lasted for more than 1 day. However, in the cases which were evaluated as good and fair the improvements lasted less than 24 hours.

From these results, we concluded that patients need adjunctive therapeutic exercise, bracing or home exercise after LLLT irradiation to enhance the efficacy of the LLLT.

\section{Discussion}

Reports in the literature which have examined the effect of LLLT in reducing spasticity in CP patients are sparse. Among the conventional spasticity attenuation 
treatments that we have carried out so far, medication is efficacious, but it also has bad points. Since medication exerts its effects systemically on the muscles in general muscles, it can cause a decline in general muscle tone and voluntary movement. Therefore, patients voluntary movement can be less smooth.

Therapeutic exercise has the potential improve the psychological relationships between patients and their physical therapists and their families. On the other hand, physical therapists need to be well-trained regarding their exercise skills. In addition it is sometimes difficult to educate families properly and it is moreover difficult to motivate patients to perform their therapeutic exercises regularly and consistently.

Bracing is effective when the brace is prescribed, produced, and fitted properly. However, the application process under the Japanese government's health insurance scheme is complicated. Botox intra-muscular injections into the spastic muscle are technically easy, yet Botox solution is expensive, so patients are financially constrained to have this approach performed as and when they want it. As another injectable approach, phenol nerve block is effective but it is technically a little complicated and it causes pain.

The relevant literature shows us that Asagai reported the efficacy of LLLT in attenuating spasticity caused by the tension athetotic type of $\mathrm{CP}$, (3) and Furukawa also reported that it LLLT was efficient for attenuation of CP-related spasticity. ${ }^{(4)}$

Cook developed a robotic system to facilitate the development of patients with severe physical handicaps, ${ }^{(5)}$ but it has unfortunately not yet been applied in the clinical therapy situation.

Moreira has reported that LLLT was effective in treatment of the spastic type of $\mathrm{CP}^{(6)}$ On the other hand, Lopriore and colleagues reported that they were unable to definitively conclude that LLLT actually facilitated the neurological development in infants, ${ }^{(7)}$ when they irradiated fetuses with LLLT. Though the mechanism by which LLLT can attenuate spasticity remains to be concretely clarified, from the existing literature we can surmise that LLLT has a direct action on the peripheral nerves which innervate the target spastic muscle, and that blood supply to the muscle and surrounding tissue is improved; LLLT exerts control of neurological function, in particular autonomic nerve control through which sympathetic hypertension is replaced with parasympathetic dominance. However, even more research is required before these mecha- nisms can be absolutely proved.

However, we consider that LLLT involves autonomic nerve control and leads to spasticity attenuation. We have been able to reach this viewpoint based on the result of a 1986 investigation which examined fluctuation of pulse wave baseline changes before and after treatment ${ }^{(8)}$ In any case, the mechanism of spasticity attenuation by LLLT is a problem which certainly merits further detailed study.

While study reports based on Evidence Based Medicine (EBM) have been released up until now, Greenhalgh introduced the idea of Narrative Based Medicine (NBM) in 1998. ${ }^{(9)}$ It states that it is natural for physicians to receive informed consent before choosing a treatment. They warned that it is difficult for physicians to create reliable relationships with patients through EBM based partial medical treatment.

It is not easy to explain NBM briefly. Basically, we understand that it is to bring "Patient Based Medicine" into clinical therapy in all medical care for patients. "Patient Based Medicine" is founded on the patients' words, the patients' ways of talking, patientbased treatments, treatments considered through patients' point of view, and so on.

In Western countries the idea of NBM introduced by Greenhalgh has continued to penetrate gradually into clinical therapy from the late $20^{\text {th }}$ century to the beginning of the $21^{\text {st }}$ century. Recently, we can see more reports about the importance of the shift from EBM. For a reference to more details about NBM, please consult Greenhalgh's textbook. In those contexts, patient-based treatment is seriously required for those who supply medical treatment.

After patients received LLLT treatment for spasticity attenuation, the patients and their families showed their appreciation. However, we were not able to approach patients well, in terms of the essence of NBM. Therefore, we will try to apply the idea of NBM to clinical therapy in treating patients from now.

\section{Conclusions}

We treated $20 \mathrm{CP}$ patients with LLLT, and in 14 (70\%) of them recognizable effects were seen. Since the duration of the effects was short, however, we have started to educate the patients' families in proper therapeutic exercise, bracing, and home exercise in order to further improve the good effects achieved by LLLT on its own in the present study. 


\section{References}

1: Walker J. B. (1985): Temporary suppression of clonus in humans by brief photostimulation. Brain Res 340: 109-113.

2: Harada T, Motegi M, Tsuruoka H (1991): Low Energy Laser Irradiation for patients with spastic paralysis. Sogo Rehabilitation, 19: 1089-1091.

3: Asagai Y, Ueno R, Miura Y, Ohshiro T (1995): Application of Low Level Laser Therapy (LLLT) on patients with Cerebral Palsy of the adult tension athetosis type. Laser Therapy, 7: 113-118.

4: Furukawa A, Hiroyasu W, Eiji N, Masaki N (2001): Effect of Low Level Laser Therapy on patients with Cerebral Palsy. Nurse Technology, 47: 107-109.

5: Cook AM, Max Meng MQH, Jason JQ, Howery K (2002): Development of a Robotic Device for Facilitating Learning by Children Who Have Severe Disabilities. IEEE: Trans Neural Syst Rehabil Eng ,
10: 178-187.

6: Moreira LA, Santos MTBR, Campos VF, Gevnevese WJ (2004): Efficiency of Laser Therapy Applied in Labial Traumatism of Patients with Spastic Cerebral Palsy. Braz Dent J, 15, SI 29-33.

7: Lopriore E, Middeldorp JM, Sueters M, Oepkes D, Vandenbussche F, Malther FJ (2007): Long-term neurodevelopmental outcome in twin-to-twin transfusion syndrome treated with fetoscopic laser surgery. American J of Obtstetrics and Gynecology, 196: 231e1-234e4.

8: Harada T, Motegi M (1986): A study of the patterns of spontaneous rhythmic fluctuations of digital plethysmogram. Jpn J Appl Physiol, 16: 247-254.

9: Greenhalgh T and Hurwita B (1998): Narrative Based Medicine. Br Med J Book (London), 3-16. 